\title{
GONÇALVES DIAS E A SEÇÃO ETNOGRÁFICA E NARRATIVA DA ÇOMISSÃO CIENTÍFICA DE EXPLORAÇÃO $(1859-1861)^{1}$
}

\author{
EDUARDO HENRIQUE BARBOSA DE VASCONCELOS ${ }^{2}$
}

$U E G$

\begin{abstract}
RESUMO: O Brasil deve ser conhecido e estudado pelos brasileiros. Essa ideia foi a força que gestou e legitimou a criação da Comissão Cientifica Exploração (CCE), criada pelos membros do Instituto Histórico e Geográfico Brasileiro com o apoio e o financiamento do governo imperial brasileiro para estimular as pesquisas sobre o "jovem" país. Dentro desse audacioso plano político-científico, o saber e o fazer etnográficos também se fizeram presentes nas ações atribuídas ao poeta/cientista Gonçalves Dias, chefe-responsável das atividades da seção etnográfica e narrativa da CCE e que deveria ter desenvolvido suas atividades na província do Ceará durante 03 anos (1859-1861). Pensar as ações da seção etnográfica e narrativa durante o período de atuação na província cearense é o objetivo deste trabalho.
\end{abstract}

PALAVRAS-CHAVE: Século XIX; Comissão Científica de Exploração; Gonçalves Dias; Etnografia; Ceará.

ABSTRACT: Brazil should be known and studied by the Brazilians. This idea was the force that justified the constitution of the Comissão Cientifica de Exploração (CCE), founded by members of the Brazilian Historic and Geographic Institute and supported by the Brazilian imperial government, in order to motivate research on the "young" country. Within this ambitious scientific and political project, ethnographic knowledge and practices were embraced in the deeds assigned to the scientist and poet Gonçalves Dias, chief of the section of ethnography and travel narrative, whom should have performed his activities in Ceará province throughout 3 years (1859-1961). To reflect on the deeds of the mentioned section during its execution is the goal of this paper.

KEYWORDS: Nineteenth Century; Comissão Científica de Exploração; Gonçalves Dias; Ethnography; Ceará.

\footnotetext{
${ }^{1} \mathrm{O}$ presente artigo é uma versão alterada do trabalho Entre a Poesia e Ciência: Gonçalves Dias e Antropologia no Ceará em Meados do XIX, apresentado na forma de comunicação oral no Grupo de Trabalho Arquivos e Histórias da Antropologia Brasileira: Tradições Visíveis e Invisíveis, sob a Coordenação da Prof. ${ }^{a}$ Dra. Christina de Rezende Rubim (UNESP) e do Prof. Dr. Antônio Carlos Motta de Lima (UFPE), durante a 26a . Reunião Brasileira de Antropologia - ABA, transcorrida de 01 a 04 de junho de 2008, na cidade de Porto Seguro/Bahia.

${ }_{2}^{2}$ Professor do Curso de História da Universidade Estadual de Goiás (UEG) - Unidade Universitária de Quirinópolis. Mestre pelo Programa de Pós-Graduação em História das Ciências e da Saúde da Fundação Oswaldo Cruz - Fiocruz/RJ. E-mail: eduardo.vasconcelos@ueg.br.
}

Espaço Ameríndio, Porto Alegre, v. 6, n. 2, p. 219-229, jul./dez. 2012. 
EDUARDO HENRIQUE BARBOSA DE VASCONCELOS - Gonçalves Dias e a seção...

No Brasil, o transcorrer do século XIX suscitou grandes efervescências políticas, sociais e culturais (GRINBERG e SALLES, 2009). Um dessas efervescências foi o périplo efetivado pela Comissão Científica de Exploração (CCE) na segunda metade do século XIX, na Província do Ceará, mas totalmente pensado e organizado como uma política científica oficial da Corte brasileira e pelo Instituto Histórico e Geográfico Brasileiro (IHGB), com o apoio e o financiamento direto do Imperador Pedro II (GUIMARÃES, 1988; SCHWARCZ, 1993). Nesse sentido, focamos o estudo nas atividades instruídas à efetivação do poeta e cientista Gonçalves Dias, encarregado dos estudos científicos dos povos nativos do Ceará provincial, embasado nos referenciais antropológicos do século XIX, adquiridos na Europa e no Rio de Janeiro e mobilizados para aplicação direta nas Províncias do Norte do Brasil, antiga denominação da atual região Nordeste do Brasil (ALBUQUERQUE Jr, 1999)3.

Nos últimos anos, uma larga produção vem sendo publicada sobre a CCE, abordando os mais diversos aspectos e as demais seções constituintes da Comissão (FIGUEIRÔA, 2005; KURY, 2001; LOPES, 1996; PINHEIRO, 2002). Tal produção vem sustentando uma visão mais dinâmica e multifacetada do que foi a ciência no século XIX, das atividades da CCE e dos trabalhos desenvolvidos pelos membros participantes da Comissão, contrastando com a concepção "áurea da ciência" e dos cientistas presente no trabalho pioneiro sobre a CCE, de autoria de Renata de Almeida Braga (1962).

Para a justificação do périplo científico, um dos aspectos legitimadores e fundamentais para a formação da CCE foi, justamente, que:

desde os primeiros tempos da colonização do Brasil, quando só a violência era capaz de abrir as portas desta colônia, tão ambicionada pelas potencias marítimas daqueles séculos, já acontecia que a terra da Santa Cruz era melhor estudada e apreciada nas viagens e relação dos escritores estrangeiros do que

\footnotetext{
${ }^{3}$ Com o intuito de facilitar a leitura dos materiais e documentos do século XIX, atualizamos a grafia dos trechos citados no presente trabalho. Todavia mantivemos a escrita original dos nomes próprios, dos topônimos e dos títulos de obras da época.
}

Espaço Ameríndio, Porto Alegre, v. 6, n. 2, p. 219-229, jul./dez. 2012. 
EDUARDO HENRIQUE BARBOSA DE VASCONCELOS - Gonçalves Dias e a seção...

nas memórias dos nossos antepassados (TRABALHOS DA COMISSÃO SCIENTIFICA DE EXPLORAÇÃO, 1862, p. II).

As terras brasileiras, mesmo sendo "melhor estudadas e apreciadas" pelos estrangeiros, isto é, europeus, instrumentalizados há muito mais tempo com as ciências e as técnicas, apresentavam como resultado de suas pesquisas:

[...] uma quantidade incrível de fatos mal estudados, de apreciações errôneas, de asserções pouco dignas de credito, coisas que lá fora terão passado por curiosas, e que dentre nós são verdadeiros disparates, mais merecedores de riso do que credores de séria constatação (TRABALHOS DA COMISSÃO SCIENTIFICA DE EXPLORAÇÃO, 1862, p. VIII).

Propiciar o conhecimento da realidade brasileira por estudiosos brasileiros bem como corrigir os erros e os fatos não verídicos a respeito do país foram os dois principais argumentos apresentados pelos sócios do IHGB para a elaboração da CCE. No entanto, os interesses da Comissão não se limitavam apenas a esses dois pontos. A produção do saber e o discurso autorizado pela ciência necessitavam do apoio dos mais vários aportes e exigiam um grande esforço de intercruzamento de dados e informações. Daí a Comissão ter diversos objetivos que, juntos, resultariam em uma visão de síntese sobre a realidade brasileira que seria estudada.

Deste modo, a Comissão foi enviada para as províncias do Norte, uma área, à época, ainda pouco conhecida (tendo com referência o sul do Brasil, então centro político, econômico e social e sede da Corte ao longo de quase todo o século XIX), onde, dentre outras atividades, avaliariam os recursos existentes e as possibilidades de exploração econômica; viajando por áreas lúgubres e locais ermos com o fim de conhecer e determinar as características e os limites de cada aérea, além de servirem, naquele momento, diretamente como os olhos e os ouvidos do Império (PRATT, 1999).

Após a discussão das vantagens e da importância dos estudos que iriam ser realizados pela Comissão Científica e, posteriormente, a aprovação do financiamento por parte do poder imperial:

Espaço Ameríndio, Porto Alegre, v. 6, n. 2, p. 219-229, jul./dez. 2012. 
EDUARDO HENRIQUE BARBOSA DE VASCONCELOS - Gonçalves Dias e a seção...

[...] dividiu-as em cinco classes ou seções, cada uma delas a cargo de um chefe, com quanto, como era natural, ficassem todos na estrita obrigação de mutuamente se coadjuvaram. [...] Para o desempenho destas cinco diferentes secções foram propostos os Srs. Conselheiro Francisco Freira Allemão, presidente da comissão e incumbido da parte botânica; Dr. Guilherme Schuch de Capanema, da geologia e mineralógica; comendador Manoel Ferreira Lagos, da zoológica; capitão-tenente Giacomo Raja Gabaglia, da astronômica e geográfica; e Antonio Gonçalves Dias, da etnográfica e narrativa da viagem (TRABALHOS DA COMISSÃO SCIENTIFICA DE EXPLORAÇÃO, 1862, p. $\mathrm{XI})$.

A Comissão representou um projeto de grande envergadura, dividida em diferentes ramos de saber, sendo composta por cinco grandes expoentes da ciência brasileira no século XIX. Após um longo período de pesquisas e estudos (1859-1861) - mais exatamente 02 anos e 05 meses de variados trabalhos - "percorreu as províncias do Ceará (sic), atingiu regiões no Piauí, Pernambuco, Paraíba e Rio Grande do Norte" (LOPES, 1996. p, 57). Infelizmente os resultados efetivos do esforço hercúleo dos membros da Comissão não puderam ser conhecidos amplamente; uma vez que todo o material e os trabalhos realizados pelos membros das cinco seções da Comissão nunca foram colocados à disposição dos cientistas e do público ${ }^{4}$, dado que todos soçobraram e, como afirma o adágio popular, foram "por água abaixo".

Explicando em outras palavras, após o desenvolvimento das atividades da CCE, foi solicitado que os resultados das pesquisas até então obtidas fossem enviados para a capital Imperial. Após carregarem e despacharem os resultados coletados, a embarcação que levava o material para o Rio de Janeiro afundou, e, com ele, a ciência brasileira

\footnotetext{
${ }^{4}$ Em um artigo de síntese sobre a CCE, a professora e pesquisadora Maria Margaret Lopes afirma que os únicos materiais referentes às atividades da CCE que ficaram intactos á água foram: "Uma série de artigos publicados nos periódicos da época dão conta de seus trabalhos no período, entre eles o jornal $\mathrm{O}$ Cearense de 1859 a 1862; o Jornal do Commercio do Rio de Janeiro; os artigos de Capanema sob o pseudônimo de Manoel Francisco de Carvalho no 'Ziguezague da Seção Geológica da Comissão Científica' publicados no Diário do Rio de Janeirco (1860-62), os Trabalhos da Commissão Scientifica de Exploração, Introdução de 1862; o primeiro folheto da Seção de Botânica (1862), e a Flora Cearense (reunindo o segundo e o terceiro folhetos) de Freire Alemão, além das publicações do IHGB; dos relatórios dos ministros dos Negócios do Império de 1856 a 1867; e a documentação de Freire Alemão, reunida na Seção de Manuscritos da Biblioteca Nacional” (LOPES, 1996, p. 57).
}

Espaço Ameríndio, Porto Alegre, v. 6, n. 2, p. 219-229, jul./dez. 2012. 
EDUARDO HENRIQUE BARBOSA DE VASCONCELOS - Gonçalves Dias e a seção...

perdeu mais de dois anos de pesquisas das cinco seções que constituíam a Comissão.

Sobre esse episódio, o médico e historiador Guilherme Studart escreveu:

A comissão tendo percorrido quase toda a província, e quando se esperava o mais útil resultado de suas explorações, naufragou o iate [navio] Invencível, que de viagem do Aracaty para o Recife levava todos os papéis, estudos e dados colhidos com grande trabalho e despesas.

Julgando o governo imperial que a referida comissão não devia continuar, foi mandada recolher-se á Corte, por aviso do Ministério do Império de 10 de maio de 1861 e para ali embarcou no dia 13 de Julho seguinte no vapor Cruzeiro do Sul (STUDART, 2001, p. 161).

Dada a amplitude e envergadura das atividades e o razoável número de seções da CCE, escolhemos no presente artigo centrarmonos, como já afirmado anteriormente, nas atividades da seção etnográfica e narrativa da Comissão científica, que tinha Gonçalves Dias como responsável maior.

Seguramente essa foi uma oportunidade única para o poeta/cientista. Pois, em 1852-1853, ele apresentou a memória intitulada Brasil e Oceania, escrita a pedido do Imperador brasileiro Dom Pedro II. Nessa obra, Gonçalves Dias tratou diretamente do estado dos indígenas no Brasil e na "quinta parte do mundo" à época dos seus respectivos descobrimentos, atentando-se para qual deles, os índios do Brasil ou da Oceania, apresentavam maiores propensões à civilização. Segundo a historiadora e pesquisadora Kaori Kodama, Gonçalves Dias cumpriu o pedido do Imperador e entregou a memória solicitada, mas essa atividade, segundo o próprio autor, careceu, à época de sua elaboração, de uma "investigação levada a campo" (KODAMA, 2007, p. 02-03).

Quase dez anos após a finalização de Brasil e Oceania, surgiu a possibilidade do poeta exercer o seu lado científico e concluir definitivamente o que havia sido solicitado a ele pelo Imperador do Brasil, participando da seção etnográfica e narrativa da CCE (KODAMA, 2007 , p. 02). Some-se a isso que o destino do périplo científico já havia sido visitado e conhecido por Gonçalves Dias, pois, tendo sido ele

Espaço Ameríndio, Porto Alegre, v. 6, n. 2, p. 219-229, jul./dez. 2012. 
EDUARDO HENRIQUE BARBOSA DE VASCONCELOS - Gonçalves Dias e a seção...

nomeado oficial da Secretaria de Estado dos Negócios Estrangeiros em 1851, foi enviado em comissão ao Ceará para inspecionar a instrução pública e recolher documentos relativos à História do Brasil nos arquivos de cartórios e mosteiros (FARIA, 201 1, p. 95).

Para o antropólogo e pesquisador Júlio César Melatti, o poeta indianista, como pesquisador, não estava à frente das ideias do seu tempo. O interesse de Gonçalves Dias pelas populações indígenas, negras e sertanejas situava-se no pensamento sobre a formação do povo brasileiro no referencial teórico que tinha como base a hierarquia das raças e as ideias de que a decadência dos índios não era motivada, mas sim acentuada pelo contato com os brancos. Seu ponto de partida era a obra do naturalista e botânico prussiano Carl Friedrich Philipp von Martius, o primeiro dos viajantes estrangeiros a tentar elaborar uma explicação para a situação em que se encontravam os índios no Brasil (MELATTI, 1993, p. 19).

Todavia, mesmo tendo desenvolvido outras atividades, Antônio Gonçalves Dias é, ainda hoje, amplamente conhecido por seus trabalhos de cunho literário, sendo considerado como o expoente máximo da primeira geração do Romantismo no Brasil (MARQUES, 2010; FARIA, 2011).

Segundo a antropóloga Silvia Porto Alegre, Gonçalves Dias não deixou nenhum trabalho escrito sobre o Ceará, e seus estudos etnográficos atualmente conhecidos referem-se exclusivamente aos índios da Amazônia, para onde ele seguiu após deixar a província cearense e as atividades da seção etnográfica e narrativa da CCE (PORTO ALEGRE, 2003, p. 28).

Sem os estudos e sem as anotações dos membros da CCE, todos perdidos durante o naufrágio da embarcação responsável pelo transporte dos materiais da CCE para o Rio de Janeiro, restaram apenas as instruções, ou os planos, que cada uma das seções deveria seguir ao longo do desenvolvimento de seus trabalhos exploratórios. Instruções essas elaboradas pelos respectivos chefes de cada seção.

Diferentemente das instruções de trabalho, que foram elaboradas por seus respectivos chefes, as instruções referentes à seção astronômica e à seção etnográfica não foram feitas por seus chefes, mas por terceiros, mais precisamente pelo Sr. Conselheiro Candido 
Baptista de Oliveira, com a primeira parte e a segunda parte sob a hábil pena do Sr. Manoel de Araújo Porto Alegre (TRABALHOS DA COMISSÃO SCIENTIFICA DE EXPLORAÇÃO, 1862, p. XII).

O responsável pela seção astronômica e o responsável pela seção etnográfica não puderam elaborar suas instruções, pois estavam a serviço na Europa, comprando os equipamentos, livros e demais materiais relativos à Comissão que não existiam - ou não eram comercializados - no Brasil. (TRABALHOS DA COMISSÃO SCIENTIFICA DE EXPLORAÇÃO, 1862, p. XII).

As instruções para a seção etnográfica e narrativa da viagem constituem um total de 16 pontos, estendendo-se da página XXXIX até a página XLV (TRABALHOS DA COMISSÃO SCIENTIFICA DE EXPLORAÇÃO, 1862), com a ausência dos resultados das pesquisas in loco, tornaramse um importante manancial de informações sobre essa empreitada científica brasileira do século XIX.

Dentre os 16 pontos elencados nas instruções para o desenvolvimento da seção etnográfica e narrativa, destacamos os seguintes:

II

[...] só se poderá adquirir noções suficientes por meios de desenhos fidelíssimos do todo, principalmente da cabeça, os que deverão ser tirados de face e de perfil $[\ldots]$.

III

[...] melhor se compararão as formas e suas variedades, as atitudes, as fisionomias e as proporções gerais do corpo: de indivíduos adultos, assim como os ângulos faciais, procurando por essa ocasião verificar se a maior abertura do ângulo atesta maior inteligência $[\ldots]$.

IV

Convém igualmente coligir crânios de toda as raças dos naturais do país, e moldar no vivo algumas cabeças para a vista de certos dados Moraes poder ser verificado conjuntamente [...] a cranioscopia deverá encontrar notáveis modificações entre as diversas protuberâncias do crânio do Índio selvagem e do Índio civilizado $[\ldots]$. 
EDUARDO HENRIQUE BARBOSA DE VASCONCELOS - Gonçalves Dias e a seção...

$\mathrm{V}$

A posição da cabeça, dos braços e das pernas, seja em repouso, na locomoção ou no trabalho, é muito significativa para um observador, porque, por ela, pelos seus movimentos, pelo seu assento sobre o pescoço se conhece o individuo....

Para alcançar os desenhos exatos acima recomendamos, ha excelente recurso da heliografia, que á sua presteza e fidelidade reúne a vantagem de não ter prevenções favoráveis ou desfavoráveis, pois seus resultados estão livres de toda a influencia de escolas ou de maneira artística: o instrumento produz tal e qual $[\ldots]$.

VIII

O estudo da língua é um complemento necessário ao estudo dos caracteres físicos.

IX

Depois dos caracteres físicos e da linguística se tratará dos costumes relativos ao individuo e a família em geral, estudando-o desde o seu nascimento até a sua morte.

XII

Será registrado tudo quanto se conhecer a respeito de sua religião, crenças e superstições [...].

XIII

Além das descrições e desenhos, far-se-há coleções de todos os enfeites, utensílios, instrumentos de musica, armas de tudo, enfim, quanto posa servir de prova da industria, usos e costumes dos indígenas [...].

Os fragmentos acima permitem uma visão geral dos aportes teóricos que orientavam os procedimentos da seção etnográfica e narrativa.

Percebe-se o grande esforço, assim como o empenho, em demarcar a diferença entre os habitantes nativos do Brasil, que deveriam ser estudados por suas características individuais e coletivas, sua(s) língua(s), suas crenças e religiões, seus hábitos e costumes, suas técnicas e indústrias e, principalmente, seus caracteres físicos, que indicariam, em suas diversas medidas corporais, suas qualidades ou seus defeitos "naturais", inerentes aos seres humanos.

Espaço Ameríndio, Porto Alegre, v. 6, n. 2, p. 219-229, jul./dez. 2012. 
EDUARDO HENRIQUE BARBOSA DE VASCONCELOS - Gonçalves Dias e a seção...

Para que isso fosse feito, contava o pesquisador com o auxílio de "um excelente recurso", a heliografia, que permitia um desenho fiel da realidade, estando, assim, livre das subjetividades do pintor e/ou desta e/ou daquela técnica que destacaria esse ou aquele detalhe que, ao final da pesquisa, pudesse interferir nos resultados e nos objetivos do estudo, levando o pesquisador a cair em erros não condizentes com a realidade estudada. O recurso da heliografia permitiria, assim, ao pesquisador captar a realidade "como ela realmente era", tornando o estudo objetivo, sem qualquer possibilidade de erro ou distorção por parte da subjetividade humana.

Desta forma, o pesquisador estaria imune, pois esteve lá e não só viu, ouviu, sentiu como trouxe (ao retornar) a prova material do que o que ele diz é realmente a realidade como ela é. Daí o nome da seção ser etnográfica e narrativa, ou seja, a etnografia seria a ciência concebida como o discurso autorizado da descrição detalhada das coisas "como elas realmente são" (CLIFORD, 1998).

As informações sobre o desenvolvimento dos estudos feitos pela seção etnográfica e narrativa são por demais pontuais, além de não pormenorizarem as atividades realizadas durante o período de sua atuação no Ceará. Mas em meados de abril de 1861, reuniram-se em Fortaleza as quatro comissões que ainda andavam na província e, na representação que fizeram ao governo Imperial, informavam que:

quanto a secção etnográfica, $V$. Ex. sabe que o chefe se acha atualmente explorando as províncias do Pará e Amazonas, para onde seguiu em Agosto do ano próximo findo, visto esta província não the oferecer a matéria mais importantes dos estudo que lhe foram encarregados (TRABALHOS DA COMISSÃO SCIENTIFICA DE EXPLORAÇÃO, 1862, p. XXXIX).

Gonçalves Dias chegou juntamente com os demais membros da Comissão em fevereiro de 1859 e, segundo o documento acima mencionado, deixou a província em agosto de 1860, totalizando um ano e seis meses de pesquisas no Ceará.

O que motivou a saída súbita e repentina do responsável pela seção etnográfica e narrativa? Qual seria a matéria tão importante, não existente e/ou não oferecida pela província que prejudicou os trabalhos de Gonçalves Dias, uma vez que a presença de Gonçalves Dias na 
EDUARDO HENRIQUE BARBOSA DE VASCONCELOS - Gonçalves Dias e a seção...

Comissão foi para coletar documentos existentes em cartórios, isto é, referentes a informações históricas, estudar os povos indígenas da região, assim como escrever sobre o transcurso e o andamento dos estudos da Comissão? Neste sentido, a crítica elaborada pelo poeta/pesquisador destinava-se à ausência de um dos elementos específicos de trabalho da seção por ele chefiada. Papéis e documentos, seguramente, desde o século XIX, não faltam no Ceará. Resta-nos então a indagação: estaria Gonçalves Dias a afirmar que no Ceará não havia índios?

\section{Referências bibliográficas}

ALBUQUERQUE Jr., Durval Muniz de. A invenção do Nordeste e outras artes. São Paulo: Cortez, 1999.

BRAGA, Renato. História da Comissão Científica de Exploração. Fortaleza: Imprensa Universitária do Ceará, 1962.

CLIFORD, James. A experiência etnográfica: antropologia e literatura no século XX. Rio de Janeiro: Editora UFRJ, 1998.

FARIA, Andréia Camila. O santo comércio da amizade: política, literatura e sociabilidade na trajetória de Gonçalves Dias. 2011. 125 f. Dissertação (Mestrado em História) - IFCH - UERJ- Rio de Janeiro, RJ, [2011].

FIGUEIRÔA, Silvia F. de M. Ciência e tecnologia no Brasil Imperial: Guilherme Schüch, Barão de Capanema (1824-1908). Varia História, Belo Horizonte, v. 21, n. 34, p.437- 455, 2005.

GUIMARÃES, Manoel Luiz Salgado. Nação e civilização nos trópicos: o Instituto Histórico e Geográfico Brasileiro e o projeto de uma História nacional. In: Estudos históricos. Caminhos da historiografia, Rio de Janeiro, v.1, n.1, p. 05-27, 1988.

GRINBERG, Keila; SALLES, Ricardo Henrique (Orgs.). O Brasil Imperial: 18311870. Rio de Janeiro: Civilização Brasileira, 2009. v. 2.

KODAMA, Kaori. O Tupi e o Sabiá: Gonçalves Dias e a Etnografia do IHGB em Brasil e Oceania. Fênix: Revista de História e Estudos Culturais, Uberlândia, v. 4, n. 3, p. 114, 2007. Disponível em: www.revistafenix.pro.br . Acesso em: 20 nov. 2012. 
EDUARDO HENRIQUE BARBOSA DE VASCONCELOS - Gonçalves Dias e a seção...

KURY, Lorelai Brilhante. A Comissão Científica de Exploração (1859-1861) In: HEIZER, Alda; VIDEIRA, Antônio Augusto Passos (Orgs.). Ciência, civilização e império nos trópicos. Rio de Janeiro: Access, 2001. p. 235-246.

LOPES, Maria Margaret. Mais vale um jegue que me carregue, que um camelo que me derrube... lá no Ceará. Hist. cienc. saude-Manguinhos, Rio de Janeiro, v. 3, n. 1, p. 5064, jun. 1996.

MARQUES, Wilton José. Gonçalves Dias: o poeta na contramão (Literatura \& Escravidão no Romantismo Brasileiro). São Carlos: EduFSCar, 2010.

MELATTI, Júlio César. Índios do Brasil. São Paulo/ Brasília: Hucitec/EdUnb, 1993.

PINHEIRO, Rachel. As histórias da Comissão Científica de Exploração (1856) na correspondência de Guilherme Schüch de Capanema. 2002. 216 f. Dissertação (Mestrado em Geociências) - UNICAMP, [2002].

PORTO ALEGRE, Maria Sylvia. Comissão das Borboletas: A Ciência do Império entre o Ceará e a Corte (1856-1867). Fortaleza: Museu do Ceará/Secretaria de Cultura do Estado do Ceará, 2003.

PRATT, Mary Louise. Os olhos do Império: relatos de viagens e transculturação. Bauru: EDUSC, 1999.

SCHWARCZ, Lilia Moritz. O Espetáculo das Raças - cientistas, instituições e questão racial no Brasil 1870-1930. São Paulo: Companhia das Letras, 1993.

STUDART, Guilherme (Barão de). Datas e fatos para a História do Ceará. II tomo. Fortaleza: Fundação Waldemar Alcântara, 2001. p 161.

Trabalhos da Comissão Scientifica de Exploração. Rio de Janeiro: Typ. Universal de Laemmert, 1862.

Espaço Ameríndio, Porto Alegre, v. 6, n. 2, p. 219-229, jul./dez. 2012. 